\title{
RISK MANAGEMENT IN THE DEVELOPMENT OF TRANSPORT PROJECTS
}

\section{Svetla Tzvetkova 1}

Received: 30.09.2020, Accepted: 21.10.2020

\begin{abstract}
The realization of transport projects is accompanied by multiple risks which vary in nature. This is determined by the specificity of the transport activity and the multitude of internal and external factors which influence it. The occurrence of risks is caused by the inability to predict events which will take place in the future. This could lead to disasters, emergency situations and a lot of negative consequences for the transport firm such as reduced productivity, low competitiveness and insufficient highly qualified work force. Therefore, risk management in the development of transport projects needs to be aimed at the development and implementation of various methods which can reduce risks or prevent the probability for occurrence of unwanted events.
\end{abstract}

Keywords: risk management in transport, development of transport projects, risk reduction methods

JEL Codes: R40, R49

\section{Introduction}

Risks are random events or a system of interlinked phenomena which inflict certain damage under specific circumstances. When it comes to the development of transport projects, there is a difference between risk and uncertainty.

Uncertainty involves inadequate and incomplete information in regards to the conditions, prerequisites, project realization and the losses that accompany them. It is associated with incompetence, accidents or the occurrence of counteraction.

\footnotetext{
${ }^{1}$ Svetla Tzvetkova, University of National and World Economy, Economics of Transport Department, Assoc. Prof., PhD, e-mail: svetlatzvetkova@abv.bg ORCID ID: https://orcid.org/0000-0002-6499-5612
} 
The term risk is usually used to define an economic situation where all probabilities for the occurrence of a certain event are known, whereas the term uncertainty is used when it is impossible to assess said probabilities.

The scope of the risk for each event in the development of most projects, including transport ones, can be defined as a function of the probability and the amount of losses resulting from its occurrence.

Risk $=f$ (probability, amount of losses)

The magnitude of the risk depends on the probability and the size of losses. If the probability for occurrence of a risk event or an expected change in losses due to its occurrence grows, so does the risk.

Risks can be managed. Project managers could adopt the necessary measures to reduce the probability for the occurrence of unfavorable situations and the scope of the damage or secure compensation for said damage in case an insurance event takes place. Risk management is part of project management.

\section{The Main Stages of Risk Management}

Risk management in the development of transport projects is a function of defining the sources of potential risk events, analyzing and evaluating risks, reacting to the occurrence of risk situations, and controlling risks in projects.

Risk management in the development of transport projects $=f$

(sources, analysis, reaction, control)

Risk management is a complicated process which needs to commence in the early stages of a project's realization since the risk of failure is at its highest precisely during that period, mainly due to lack of information (Zarenkov, 2011). In the later stages of the project, the financial risks associated with its realization become more important.

Figure 1 presents the main stages of management in the development of transport projects. 
Figure 1. Stages of risk management in the development of transport projects

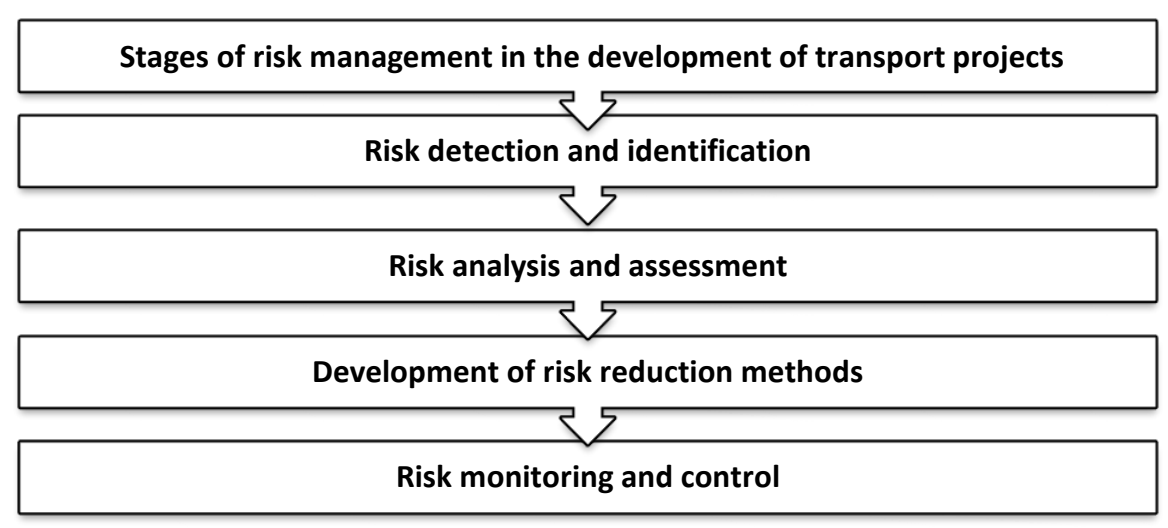

- Risk detection and identification is carried out on the basis of previously established systems which guarantee security and safety during production activity in transport; they can identify possible future risks during transportation processes, loading and unloading operations, risk situations, passenger incidents, etc.;

- Risk analysis and assessment is based on the detection of risk factors and the evaluation of their influence on the project realization process. Firstly, individual factors are detected, followed by their combined influence on the development of transport projects;

- Development of risk reduction/management methods. At this stage, a preemptive assessment is made of the negative consequences from the occurrence of risk situations in order to avert them. First and foremost, standards are determined with a view to achieving more high-quality transport services; the necessary information about the management team is collected and purposeful company policies and risk management systems are implemented. This involves the development of company strategies and measures for carrying out specific undertakings aimed at preventing or reducing the negative effects of risks;

- Risk monitoring and control is the final stage, where a plan for monitoring and control of the risk reduction process is developed.

The modern concept of management views risk management as a continuous process where risks are identified, analyzed and measured, ways of working with them are sought, and the effectiveness of previously adopted measures is evaluated. A great deal of uncertainty is involved in terms of the 
decision-making process and the taking of specific steps in the management of transport project development. In a broad sense, uncertainty is inadequate information about the conditions of a project's realization. It is provoked under the influence of the following factors:

- incomplete knowledge about all parameters of the situation in terms of selecting an optimal solution, as well as the presence of probability characteristics in the environment's behavior;

- the presence of a chance factor, i.e. the implementation of factors which cannot be foreseen or prognosticated, even in probability execution;

- the presence of subjective factors for counteraction when the decision-making process is carried out in a situation of playing with partners with opposite or non-concurrent interests.

Uncertainty and the risks which accompany management during project development are two interlinked categories.

\subsection{Determining the Sources of Hypothetical Risks}

There are two types of risk which could emerge in the transport project management process. The first one, which corresponds to pure uncertainty, is the "catastrophic risk", where there is a probability for the occurrence of irreversible losses of assets as a result of the infliction of irreparable damage on economic subjects. It is caused by unforeseen changes in the influence of a number of internal and external factors. The second type of risk is defined as "dynamic" and it involves the so-called "speculative uncertainty". It is caused by the occurrence of unforeseen changes in the value of the examined subject under the influence of external factors such as fluctuations in the economic situation or inadequate management decisions. The difference between the two types of risk is the fact that static risk could be a one-time occurrence and disrupt the realization of the project (Parvanov, H., Bakalova, V., Tzvetkova, 2010), whereas the dynamic risk could occur multiple times in the project management process without leading to its disruption. Both types of risk result in complete or partial loss of invested capital, and their magnitude depends on the political, social, economic and ecological situation.

Given the specific peculiarity of the transport activity and the wide range of difficulties which emerge in the planning, organization and adequate realization of freight processes during project management in transport, the fundamental factors which could have significant influence over it should also be taken into account, as they could cause the occurrence of serious emergency situations which in turn could result in potential losses. 
Figure 2 systematizes the fundamental groups of factors inherent to the transport activity which could lead to negative consequences for a project.

Figure 2. Factors which influence transport activity

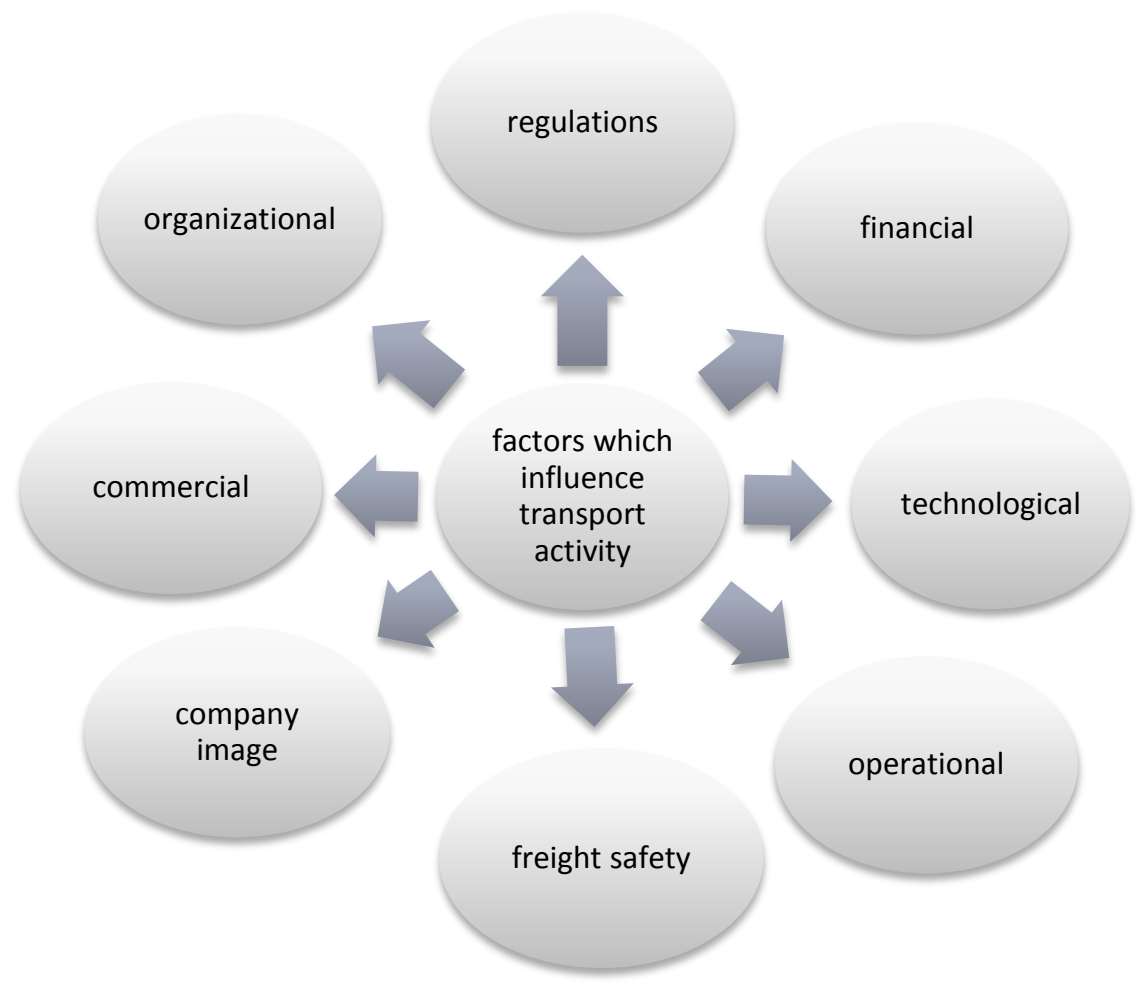

- $\quad$ Regulations are implemented in regards to market access namely, obtaining a license for transport activity. Said license could be revoked if violations in terms of financial stability and professional competence are detected in the company. Risks for regular transport activity could also occur if legal requirements within the mandatory prescriptions, standards, contract clauses, etc. are not strictly implemented;

- Organizational factors emerge during the realization of the transport activity, in the organization and planning of the activity, the management of human resources and their effective use, as well as the imposing of a specific type of organizational culture in the company; 
- $\quad$ Financial factors are directly associated with the use of financial resources and strict adherence to budget, observation of tax liabilities and payment of employment obligations. Financial risks occur mainly when the losses exceed the planned resources for a project or when the prime cost exceeds the value of the planned revenue;

- The commercial factor is associated with the market situation, more specifically the implementation of a marketing strategy, as well as the competition in force on the market;

- Technological and operational factors emerge in regards to the use of the rolling stock, the accrual of depreciation, and the effective organization of technical maintenance and repair activities;

- Company image/reputation is associated with inadequate company behavior, underestimation of existing and potential competitors, drops in the quality of supplied transport services, etc.;

- Freight safety and security involves risks which are dependent and connected to the overall activity of transport enterprises management of assets and personnel, development of an effective information infrastructure, observation of enforced regulations and procedures in the field of intellectual property, and incorporation of new technology in the field of freight activity.

\subsection{Risk Analysis and Assessment}

Risk analysis and assessment is one of the most important stages of risk management in the development of transport projects. The quality of the assessment greatly influences the determination of the actions that an enterprise will take in order to reduce risks.

Once the risks have been defined, a qualitative assessment needs to be made in order to determine the probability for occurrence of a risk event, as well as the extent to which it will affect the realization of a project. To that end, it is appropriate that a risk parameter assessment matrix be created.

Table 1. Risk parameter assessment matrix

\begin{tabular}{|l|r|l|r|l|}
\hline \multicolumn{1}{|c|}{ Risk event } & $\begin{array}{c}\text { Probability for } \\
\text { occurrence }\end{array}$ & $\begin{array}{c}\text { Influence on } \\
\text { the project }\end{array}$ & $\begin{array}{c}\text { Time of } \\
\text { occurrence }\end{array}$ & $\begin{array}{c}\text { Probability for } \\
\text { prevention }\end{array}$ \\
\hline $\begin{array}{l}\text { Changes in } \\
\text { fuel prices }\end{array}$ & high & average & $\begin{array}{r}\text { within a } \\
\text { year }\end{array}$ & low \\
\hline Event .... & & & & \\
\hline Event .... & & & & \\
\hline
\end{tabular}


Risk analysis employs various methods that require the collection of different types of information:

- the expertise method;

- comparisons to analogous projects and risks;

- $\quad$ building a tree of decisions;

- $\quad$ imitative modeling;

- $\quad$ analysis of sensitivity to alternative solutions;

- $\quad$ experience from previously realized projects, etc.

Usually, there are two stages of risk analysis and assessment: qualitative and quantitative.

Figure 3.Algorithm for qualitative/quantitative analysis and risk assessment

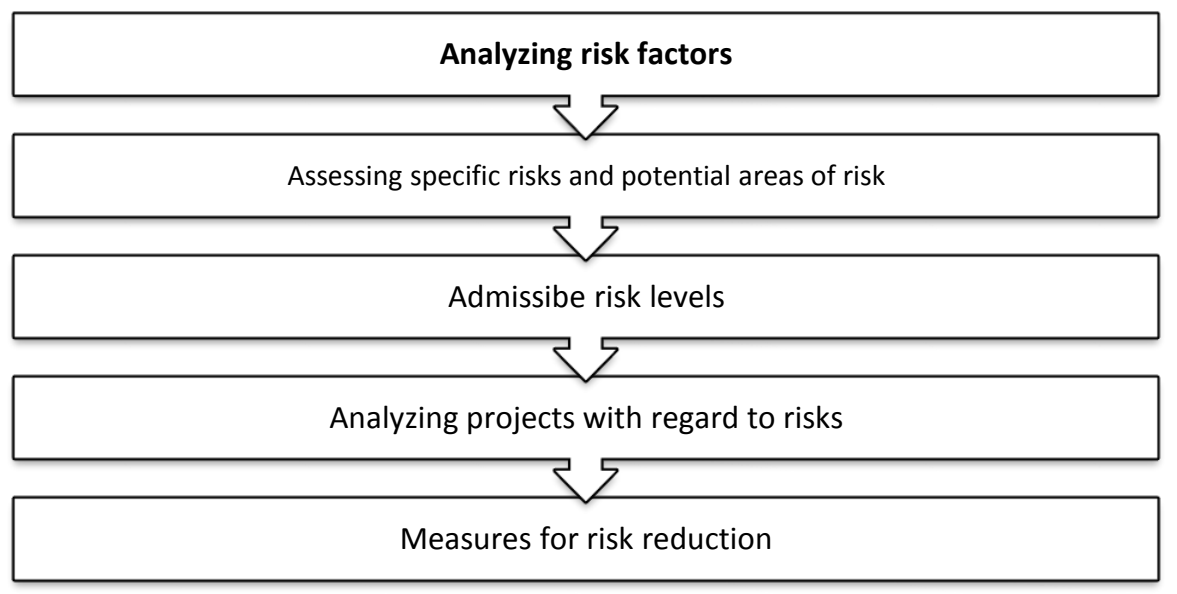

\subsection{Risk Reduction Methods in the Development of Transport Projects}

Transport enterprises always face an abundant variety of risks in the management of project development. The diversity in risks is quite large - fires, disasters, international conflicts, changes in the legislation that regulates transport activity, inflation fluctuations, etc.

The high degree of risk occurrence in the management of transport project necessitates the pursuit of ways for their artificial reduction. In the practice of project management, the following risk reduction methods are implemented: 
- $\quad$ Risk diversification - by predicting drops in the demand for offered transport services, transport enterprises seek new market niches for work or focus their activity towards performing other types of services or providing ones which accompany the main one. Diversification offers two primary ways of managing risks - active and passive. The active tactics of transport enterprises for realization of the transport production on the market involves, on one hand, careful research, examination and realization of the most effective investment projects, conquest of a significant portion of the transport market with specialization in one type of transport services, and, on the other hand, fast reorientation from one type of transport services to another, including possible conquests of other markets. Passive risk management is characterized by low turnover or a minimal level of concentration of the volume of work;

- $\quad$ Risk allocation among participants in the transport activity - the standard practice of risk allocation consists of assigning the responsibility for risks to a transport activity participant who is more qualified than everyone else to identify and control risks. Risk allocation is carried out during the development of a project's financial plan and contractual documentation. It should be taken into account that any rise in the risk levels of one participant should be accompanied by adequate changes in the distribution of the profits from the project. Therefore, what should be accounted for first and foremost during negotiations is the capacity of project participants with regard to preventing unfavorable consequences from the potential occurrence of risks. An acceptable remuneration for the risk should be negotiated, and the parity in the correlation between risk and profit among all participants in the transport project should be observed. The higher the degree of the risk which the participants are willing to allocate to their partners is, the harder it becomes to attract funding for the transport activity from experienced investors. Therefore, it is advisable that participants in the transport project display maximum flexibility in terms of what share of the risk they are willing to take on during negotiations. Participants who are willing to discuss the issue of taking a large portion of the risk could convince experienced investors to lower their requirements;

Insurance - in essence, risk insurance is the process of passing certain risks on to insurance companies. Insurance covers all risks, including exceptional circumstances, extending to the carriage of loads from one warehouse to another, i.e. it covers the entire transportation process, including ground transportation to the port of loading and from the port of unloading. This form of insurance is usually implemented for borrowed equipment as well. Moreover, it 
is often used as protection from the consequences of material damage to transport vehicles/facilities;

Coverage of unforeseen expenses is a risk reduction method which involves the determination of a correlation between potential risks which affect a project's cost and the amount of expenses necessary to overcome losses. The magnitude of said amount should be equal or larger than the magnitude of the fluctuations of system parameters in time. A $7-12 \%$ increase in the project's overall cost is permissible for setting aside reserve resources planned for the occurrence of exceptional circumstances (Parvanov, H., Bakalova, V., Tzvetkova, 2010). Additional sources of funding for the project should also be set aside, and reserve funds where deductions amounting to a certain percentage of the realization of transport services should be created. In order to reduce risks during the development of a project's financial plan, a significant reserve needs to be created to guarantee stability during the realization of a project's stages; additional expenses, as well as temporary drops in the supply of transport services should also be taken into account;

- Written negotiation or reception of guarantees for reduction of the risks for transport enterprises, etc.

\subsection{Monitoring and Control}

Once the risk reduction measures have been implemented, their effectiveness needs to be evaluated. A qualitative analysis of risks is made, and the expenses for their minimization are compared to the amount of losses resulting from the occurrence of risk events. After that, the project manager decides whether a certain level of risk is admissible or not.

\section{Conclusion}

The management of projects during their realization is an activity which is directly associated with the improvement of resource utilization along the EU's operational programns. Effective project management practically means the achievement of significant economic and social effects, especially organizational-technological measures and activities on the basis of improving the connections and the interaction between the individual components of business systems (Parvanov, H., Bakalova, V., Tzvetkova, 2010).

For a transport project to be realized successfully, the appropriate approaches and the optimal combination between them need to be pursued in order to reduce the risks which are too vast and varied. Among the main goals of risk reduction in the development of projects in transport enterprises is the 
rationalization of a transport enterprise's relationships with its partners, consignors, recipients and insurers.

The modern concept of risk management views it as a continuous process where risks are identified, analyzed and measured, methods and approaches for their reduction are sought, and the effectiveness of previously adopted measures is evaluated.

\section{REFERENCES}

Zarenkov, V., (2011), "Project Management", Varna: City Auto Center Publishing House;

Parvanov, H., Bakalova, V., Tzvetkova, S., (2010), "Management of Transport Projects", Sofia, University Publ. House "Stopanstvo";

Projektmanagement Manufaktur: Methoden, Insights, Know-How; http://projektmanagement-manufaktur.de/risikoanalyse-projektmanagement;

Die Umsetzungsberatung https://www.umsetzungsberatung.de/projektmanagement/risikomanagement.php 